\title{
MORFO-ANATOMIA DA SEMENTE DE Euterpe precatoria Mart. (Palmae) ${ }^{1}$
}

\author{
MADALENA OTAVIANO AGUIAR², MARIA SÍLVIA DE MENDONÇA ${ }^{3}$
}

\begin{abstract}
RESUMO - Euterpe precatoria, vulgarmente conhecida como açaizeiro, é bastante popular na Região Norte pela produção de uma bebida saborosa, obtida da polpa do fruto, conhecida como "vinho do açaî". Neste trabalho foi feita a descrição morfo-anatômica da semente madura de Euterpe precatoria, com o intuito de contribuir para estudos de micropropagação e produção de mudas da referida espécie. As observações foram feitas em secções longitudinal e transversal da semente, utilizando-se lupa binocular e microscópio óptico. A semente é albuminosa, com forma globosa e preenche a maior parte do fruto, tendo um único poro germinativo. O endosperma é volumoso, homogêneo, sólido e duro. O embrião é indiviso, cônico e basal. O eixo embrionário é curvo, com pólo radicular indiferenciado e pólo caulinar diferenciado em três primórdios foliares.

Termos para indexação: morfologia, anatomia, semente, palmeiras, Euterpe precatoria.
\end{abstract}

\section{MORPHO-ANATOMY OF THE SEEDS OF Euterpe precatoria Mart.}

\begin{abstract}
Euterpe precatoria (Palmae) commonly known as "açaizeiro" is very popular in the northern region of Brazil for the production of a delicious drink, obtained from the pulp of the fruit, known as açaí wine. In this paper, the morpho-anatomic description of the mature seeds of Euterpe precatoria was made, aiming to contribute to studies of micro-propagation and seedling production. The observations were made in the longitudinal and transversal sections of the seeds, using a binocular stereoscope and an optical microscope. The seed has a globe-shaped form and occupies the most part of the fruit, with only one germination pore and has a volumous, homogeneous, solid and hard endosperm. The embryo is not divided, and is conical and basal, the embryo axis is curved, with the primary root pole that is not differentiated and the epicoty pole is differentiated into three primordial leaves.
\end{abstract}

Index terms: Euterpe precatoria, palm, seed, morphology, anatomy.

\section{INTRODUÇÃO}

Euterpe precatoria é vulgarmente conhecida como açaído-amazonas, açaí-solitário e juçara. Está distribuída por toda a região Amazônica (Knah \& Granville, 1992), sendo uma das espécies mais difundidas e comuns da família e do gênero, nos Neotrópicos (Henderson, 1995). Calzavara (1972) e Castro (1992) consideram as espécies E. precatoria, E. oleracea e $E$. edulis como as mais importantes do gênero.

O mesocarpo comestível é a parte mais utilizada do fruto de E. precatoria, de onde é extraído, a partir de frutos fres-

\footnotetext{
${ }^{1}$ Aceito para publicação em 22.05.2003; parte da Dissertação de Mestrado apresentada ao INPA/UA pela primeira autora.

${ }^{2}$ M.Sc. em Botânica; R.15, 300, Conj. Colina do Aleixo, 69083-570, Manaus-AM; e-mail:motaviano@fua.br

${ }^{3}$ Prof. Titular, Dra., LABAF/DCFDA/FCA/UA; e-mail:msilvia@fua.br
}

cos, um líquido espesso conhecido como "vinho de açaî", amplamente consumido na Amazônia brasileira em todos os níveis sócio-econômicos da população (Castro, 1992). Segundo Anderson (1977), E. precatoria é uma das palmeiras mais usadas por uma tribo dos índios Yanomama, fornecendo palmito e madeira de qualidade superior. $\mathrm{O}$ uso medicinal também é citado por alguns autores como Prance \& Silva (1975), Knah \& Granville (1992), Henderson et al. (1995).

A semente constitui-se num dos principais mecanismos de propagação das palmeiras, principalmente daquelas que não têm perfilhos como E. precatoria. Algumas informações sucintas sobre o fruto e a semente de E. precatoria são encontradas nos trabalhos de Chaves \& Pechnick (1945), Jordan (1970), Kahn (1988), Castro (1992,1993), Bovi \& Castro (1993), Henderson \& Scariot (1993), Henderson (1995) e Henderson et al. (1995). 
Diante da escassez de informações mais detalhadas sobre a semente de E. precatoria, o presente trabalho propõe-se a descrever a morfo-anatomia de sua semente como contribuição aos estudos posteriores no campo da engenharia genética, micropropagação "in vitro" e produção de mudas, entre outros.

\section{MATERIAL E MÉTODOS}

As sementes foram retiradas de frutos maduros, coletados de cinco matrizes de cada área, situada no mini-campus da Universidade do Amazonas e na Rodovia AM-010 (Km 9 e 13). Foi obtida, aleatoriamente, uma amostra de 30 frutos por área. Retirou-se manualmente a polpa e a parte fibrosa dos frutos, obtendo-se as sementes. As observações da semente foram feitas a olho nu e utilizando-se lupa binocular. A estru- tura anatômica foi observada por meio da microscopia óptica, em cortes longitudinais e transversais da semente. Para preparação dos cortes anatômicos, o material foi previamente fixado em $\mathrm{FAA}_{50}$, desidratado progressivamente pelas misturas de etanol-butanol, incluído na parafina a $58^{\circ} \mathrm{C}$ (Kraus \& Arduin, 1997), confeccionados em micrótomo automático rotativo, corados com Astrablau e Fucsina básica (Patiño, 1986) e, finalmente, montados em bálsamo do Canadá. As fotomicrografias foram feitas em fotomicroscópio Axioskop, com câmara MC-80.

\section{RESULTADOS E DISCUSSÃO}

A semente de Euterpe precatoria preenche a maior parte do fruto (Figura 1A), apresenta forma globosa, coloração marrom escuro e diâmetro médio de 11,5 mm. Apresenta uma
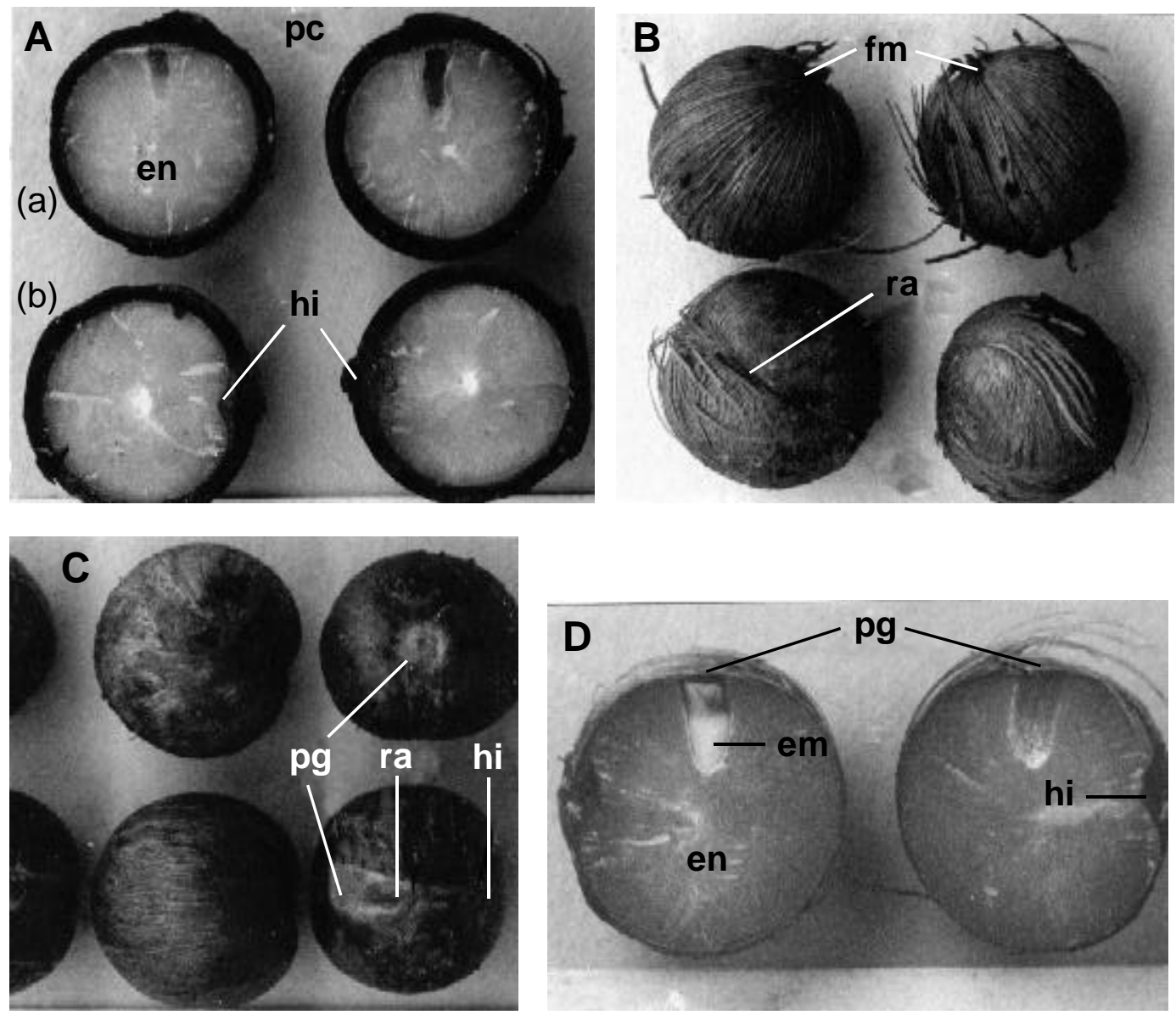

FIG. 1. Frutos e sementes deEuterpe precatoria. A: frutos em secção longitudinal (a) e transversal (b); B: sementes com fibras; C: sementes sem fibras; D: detalhe da posição do embrião na semente.

Legenda: Em - embrião; En - endosperma; Fm - fibras mesocárpicas; Hi - hilo; Pc - pericarpo; Pg - poro germinativo; Ra - rafe. 
depressão, a rafe, onde em uma de suas extremidades localiza-se o poro germinativo e, na outra, o hilo (Figura 1C). Feixes de fibras partem da região do hilo, formando um tufo de tecido fibroso sobre o poro germinativo, que é facilmente observado quando a polpa é retirada (Figura 1B).

O tegumento é delgado, constituído por várias camadas de células que podem ser agrupadas em três estratos distintos (Figura 2A e B). Nos estratos externo e médio, as células são grandes, de paredes grossas, sendo que no estrato externo as células apresentam um conteúdo celular tanífero e somente neste estrato foram observados feixes vasculares. $\mathrm{O}$ estrato interno é constituído por uma ou duas fileiras irregulares de células pequenas, de paredes delgadas, com conteúdo celular tanífero, limitando-se ao endosperma de forma ondulada, não penetrando no mesmo.

Fragmentos do endocarpo permanecem aderidos ao tegumento após a retirada do mesocarpo, apresentando células de paredes engrossadas e feixes vasculares (Figura 2A). De acordo com Tomlinson (1990), nas sementes das palmeiras, o endocarpo continua aderido ao tegumento quando o mesocarpo é retirado, consistindo basicamente de tecido esclerificado que pode ou não conter feixes vasculares.

Na região hilar dá-se uma expansão progressiva do estrato externo do tegumento, alcançando sua extensão máxima. Nesta região, o diâmetro das células e dos feixes vasculares é maior e o tecido é mais frouxo, com pequenos espaços entre as células (Figura 2B).

O endosperma ou albúmen é volumoso, homogêneo, sólido, duro, branco prateado e brilhante (Figuras 1A e D), com células de paredes bastante grossas, sendo visualizados campos primários de pontuações (Figura 2C).

Entre as espécies do gênero Euterpe, o caráter homogêneo do endosperma foi observado em $E$. precatoria (Henderson et al, 1995) e E. edulis (Belin-Depoux \& Queiroz, 1971) e, o ruminado, é característico de E. oleracea (Paula, 1975). Entretanto, de acordo com Tomlinson (1990), esta característica do endosperma é, algumas vezes, insignificante, porque não distingue grupos maiores e pode ser diferente dentro de um mesmo gênero. Henderson (1995) refere-se às espécies do gênero Euterpe com predominância de endosperma homogêneo, sendo o tipo ruminado pouco freqüente.

O embrião de E. precatoria é indiviso, cônico e pequeno em relação ao volume total de endosperma, com cerca de 2 a 4 mm (Figura 1D). De acordo com Alves \& Demattê (1987), essa desproporção é devido ao pouco desenvolvimento do embrião, que precisará das substâncias aleurônicas e amiláceas, contidas no endosperma, para seu desenvolvimento.
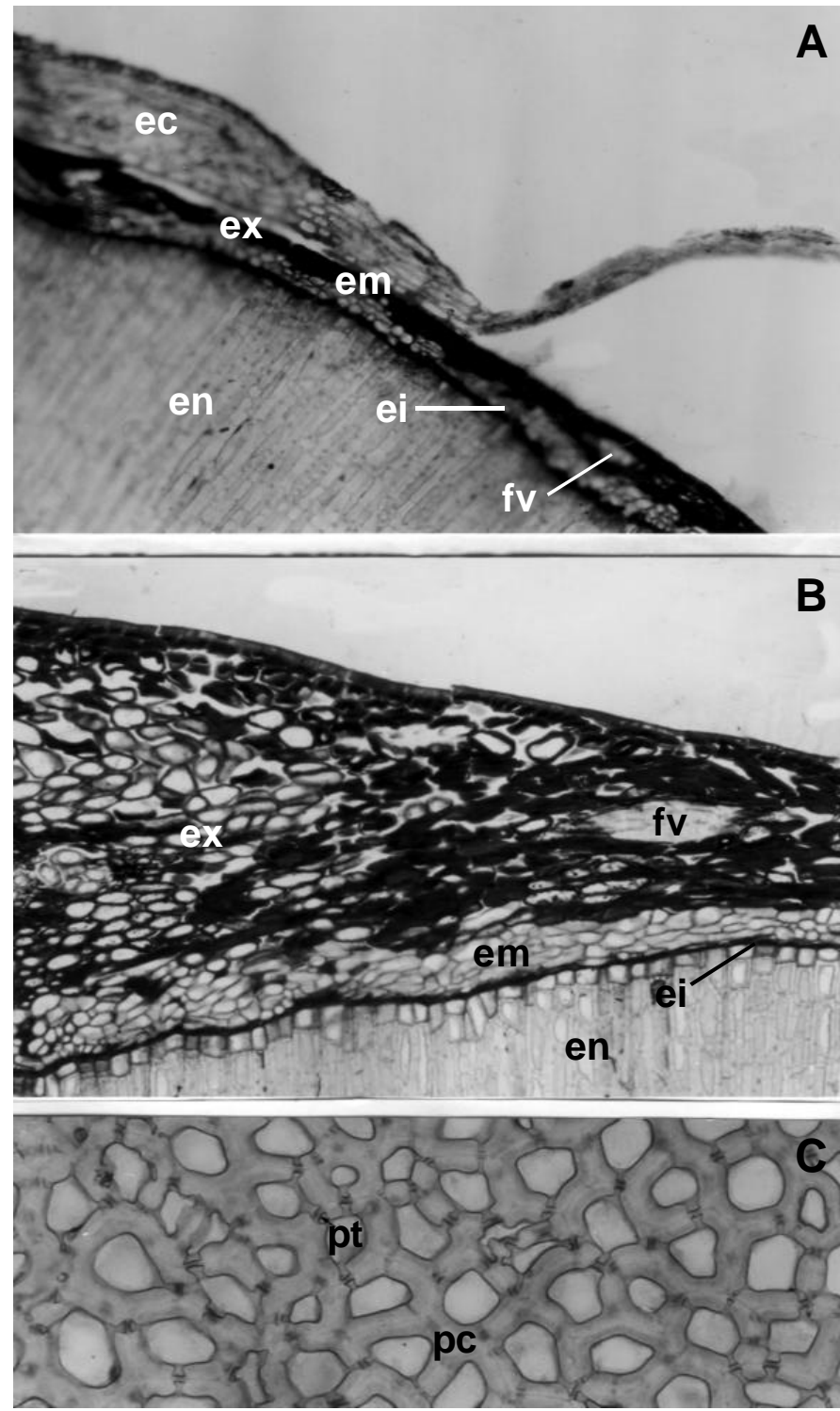

FIG. 2. Semente de Euterpe precatoria em secção transversal. A: tegumento com endocarpo; B: região hilar; $C$ : endosperma.

Legenda: Ec - endocarpo; Ei - estrato interno; Em - estrato médio; En - endosperma; Ex - estrato externo; Fv - feixes vasculares; Pc parede celular; $\mathbf{P t}$ - pontuações.

Em algumas espécies de palmeiras como Elaeis guineensis (Hartley, 1977), Cocos nucifera (Sugimura \& Murakami, 1990) e Euterpe oleracea (Pinheiro, 1992), o embrião apresenta uma constrição que o divide em duas regiões. Em E. precatoria esta constrição no embrião aparece sutilmente, entretanto, as duas regiões podem ser distinguidas por meio da coloração, onde em material fresco, logo após a retirada do embrião da semente, a porção mais alargada é 
amarelo-esbranquiçada e corresponde a região proximal e, a porção mais estreita é mais clara, de cor branca-pálida e corresponde à região distal (Figuras $1 \mathrm{D}$ e $3 \mathrm{~A}$ ).

$\mathrm{Na}$ região proximal do embrião está localizado o eixo embrionário, onde se observa em vista frontal, uma minúscula elevação central por onde sairá a raiz primária (Figura 3B). Esta elevação também foi observada por Dassanayake \& Sivakadachchan (1973) no embrião maduro de Borassus flabellifer.

A região distal é percorrida por muitos feixes vasculares e, durante a germinação será transformado em órgão de ab- sorção, o haustório. Esta região, segundo Alves \& Demattê (1987), é tida por muitos autores como o verdadeiro cotilédone das palmeiras, pois tem a função de dissolver e absorver o endosperma, já a região proximal é considerada apenas como uma bainha que protege o eixo embrionário.

O eixo embrionário é curvo, com posição oblíqua em relação ao eixo do cotilédone e apresenta dois pólos meristemáticos: o pólo radicular e o pólo caulinar (plúmula) (Figura 3B). O pólo radicular, nesta fase, ainda está indiferenciado e localiza-se em posição central e periférica ao eixo da região proximal do embrião. Em Borassus
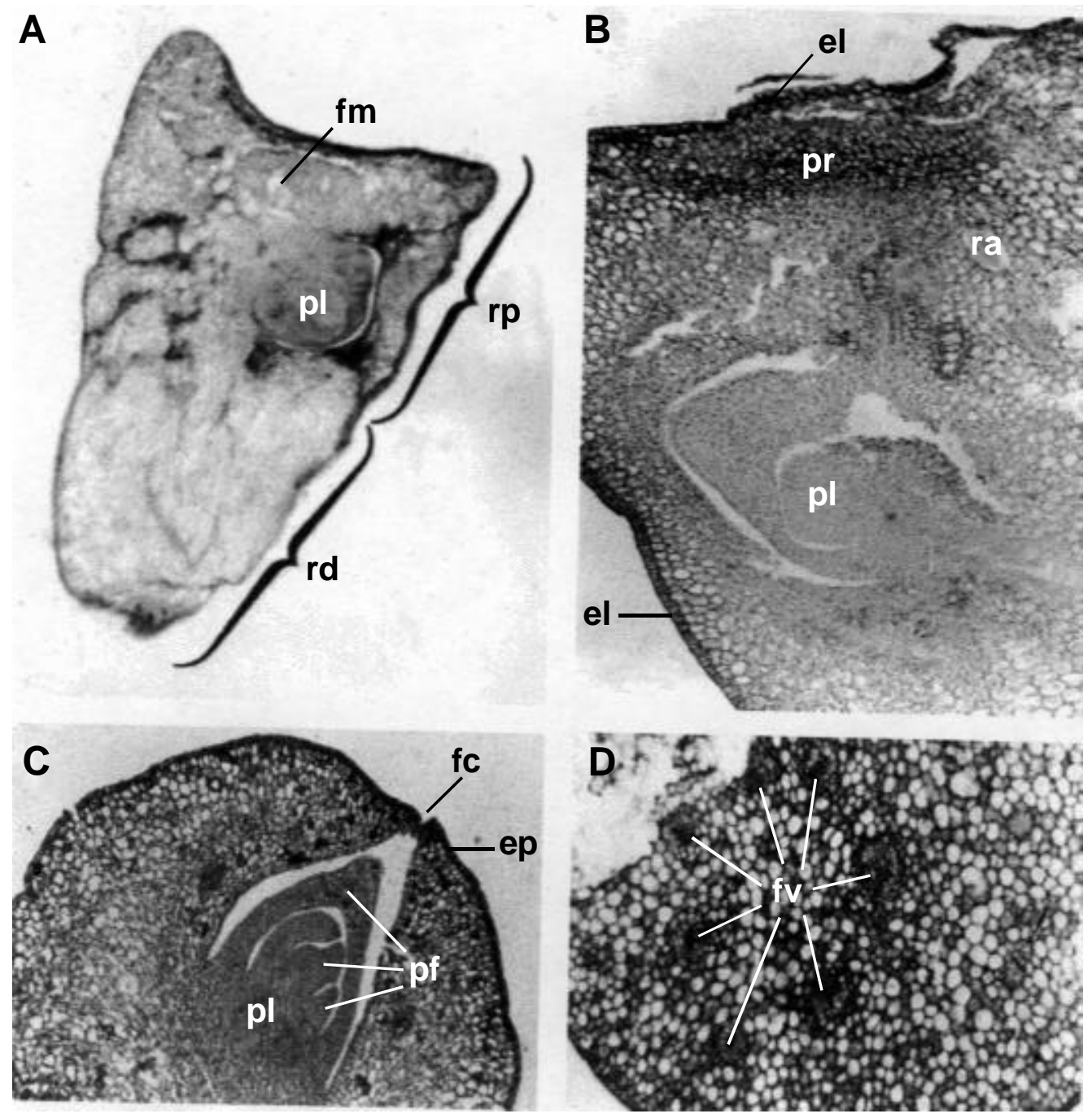

FIG. 3. Embrião de Euterpe precatoria em secção longitudinal (A e B) e transversal (C e D). A: aspecto geral do embrião; B: detalhe do eixo embrionário; $C$ : aspecto geral da plúmula; D: detalhe dos feixes vasculares.

Legenda: C - cavidade; El - elevação; Ep - epiderme; Fc - fenda cotiledonar; Fv - feixes vasculares; Pf primórdios foliares; PI - plúmula; Ra - ráfides; Rd - região distal; $\mathbf{R p}$ - região proximal; Pr - região do pólo radicular. 
flabellifer (Dassanayake \& Sivakadachchan, 1973) e Elaeis guineensis (Hartley, 1977) o pólo radicular também é indiferenciado. Segundo Haccius \& Philip (1979), em embriões de Cocos o pólo radicular somente começa a se reorganizar no inicio do desenvolvimento dos primórdios foliares.

A plúmula esta localizada em posição lateral ao eixo da região proximal do embrião. É diferenciada em três primórdios foliares que estão alojados dentro de uma cavidade no cotilédone (Figura 3C). A cavidade é revestida por uma epiderme uniestratificada de células achatadas que revestem também o primeiro primórdio. Os demais primórdios foliares são separados, um do outro, por uma epiderme semelhante.

Em corte transversal, é possível observar a posição perpendicular dos primórdios foliares em relação ao eixo longitudinal do embrião, assim como, a forma aguda dos mesmos. No cotilédone há uma fenda perpendicular ao eixo embrionário, na direção do ápice dos primórdios, unindo ambas as epidermes: a externa que reveste o embrião e a da cavidade da plúmula (Figura 3C). Durante a germinação esta fenda, pressionada pela plúmula, se abre permitindo sua emergência. Tal fenda também foi observada por Hartley (1977) em Elaeis guineensis, que a denominou de fenda cotiledonar, em Euterpe edulis (Belin-Depoux \& Queiroz, 1971) e em Cocos nucifera (Sugimura \& Murakami, 1990). Todavia, nem sempre esta fenda é formada no cotilédone. Dassanayake \& Sivakadachchan (1973) observaram que apesar do embrião maduro de Phoenix dactylifera e Borassus flabellifer serem muito semelhantes, a abertura não é encontrada neste último e o cotilédone cerca totalmente a plúmula que, para emergir, dilacera o mesmo.

Em corte transversal da região distal, logo abaixo da plúmula, observa-se sete feixes vasculares que se destacam dos demais por terem maior diâmetro e por estarem distribuídos em círculos. Possivelmente, estes saem diretamente da plúmula e se ramificam em feixes menores, que se distribuem desordenadamente no cotilédone (Figura 3D).

\section{CONCLUSÕES}

- A semente de Euterpe precatoria tem endosperma volumoso, sólido e homogêneo de coloração branco prateado, e um único poro germinativo, recoberto pelo tegumento.

- O embrião é indiviso e cônico, distinguindo-se uma região distal, mais estreita e percorrida por muitos feixes vasculares, e uma região proximal, mais alargada de colo- ração mais escura, apresentando, em vista frontal, uma minúscula elevação central por onde sairá a raiz primária.

- O eixo embrionário é curvo e está localizado na região proximal do embrião. Tem o ápice radicular indiferenciado e o ápice caulinar diferenciado em três primórdios foliares, que estão em posição perpendicular ao eixo longitudinal do embrião.

- No cotilédone há uma fenda perpendicular ao eixo embrionário, na direção do ápice dos primórdios foliares, através da qual dá-se a emergência dos folíolos.

\section{REFERÊNCIAS}

ALVES, M.R.P.; DEMATTÊ, M.E.S.P. Palmeiras: características botânicas e evolução. Campinas: Fundação Cargill, 1987. 129p.

ANDERSON, A.B. Os nomes e usos de palmeiras entre uma tribo de índios Yanomama. Acta Amazonica, Manaus, v.7, n.1, p.5-13, 1977.

BELIN-DEPOUX, M.; QUEIROZ, M.H. Contribuition à l'étude ontogénique des palmiers. Quelques aspects de la germination de Euterpe edulis Mart. Revue Générale de Botanique, Paris., n. 78, p.339-371, 1971.

BOVI, M.L.A.; CASTRO, A. Assaí. In: CLAY, J.W., CLEMENT, C.R. (Ed.) Income generativy forests and conservation in Amazonia. Rome: FAO, 1993. p.58-67. Forestry Paper.

CALZAVARA, B.B.G. As possibilidades do açaizeiro no estuário amazônico. Boletim Faculdades Ciências Agrarias, Belém, n.5, p.165-230, 1972.

CASTRO, A. O extrativismo do açaí no Amazonas. In: RELATÓRIO de resultados do projeto de pesquisa: extrativismo na Amazônia Central, viabilidade e desenvolvimento. Manaus: INPA-CNPq/ ORSTOM, 1992. p.779-782.

CASTRO, A. Extractive exploitation of the açaí (Euterpe precatoria) near Manaus, Amazonia. Tropical forests, people and food: biocultural interactions and applications to development, Paris, v.15, p.779-782, 1993.

CHAVES, M.J.; PECHNICK, E. O assaí, um dos alimentos básicos da Amazônia. In: CONGRESSO DA ASSOCIAÇÃO QUÍMICA DO BRASIL, 1945, São Paulo. p.169-172.

DASSANAYAKE, M.D.; SIVAKADACHCHAN, B. Germination and seedling structure of Borassus flabellifer L. Ceylon Journal of Science, Ceilão, v.10, n.2, p.157-164, 1973.

HACCIUS, B.M.; PHILIP, K.V.J. Embryo development in Cocos nucifera $\mathrm{L} .:$ a critical contribution to general understanding of palm embryogenesis. Plant Systematics and Evolution, Calicut, v.132, p.91-106, 1979.

HARTLEY, C.W.S. The oil palm. London: Longman, 2. ed., 1977. 806 .

HENDERSON, A.; SCARIOT, A. A flórula da Reserva Ducke, I: Palmae (Arecaceae). Acta Amazonica, Manaus. v. 23, n.4, p.349369, 1993. 
HENDERSON, A. The palms of the Amazon. Oxford: University Press, 1995. 362p.

HENDERSON, A.; GALEANO, G.; BERnAL, R. Palms of the Americas. New Jersey: Princeton University Press, 1995. 352p.

JORDAN, C.B. A study of germination and use in twelve palm of northeastern Peru. Principes, v. 14, n.1, p.24-32, 1970.

KAHN, F. Ecology of economically important palms in Peruvian Amazonia. Advances in Economic Botany, New York, n.6, p.4249, 1988.

KAHN, F.; GRANVILLE, J. Palms in forest ecosystems of Amazonia. Ecological Studies, New York, n.95, 226p. 1992.

KRAUS, J.E.; ARDUIN, M. Manual básico de métodos em morfologia vegetal. Rio de Janeiro: EDUR, 1997. 198p.
PATIÑO, J.C. Microtecnia vegetal. México: Trillas, 1986. 106p.

PAULA, J.E. Anatomia de Euterpe oleracea Mart. (Palmae da Amazônia). Acta Amazonica, Manaus, v.5, n.4, p.265-278,.1975.

PINHEIRO, L.H.B. Aspectos morfológicos da semente e plântula do açaí (Euterpe oleracea Mart. - Arecaceae). Manaus: Universidade do Amazonas, 1992. 49p (Monografia).

PRANCE, G.T.; SILVA, M.F. Árvores de Manaus. Manaus: CNPq/ INPA. 1975. 312p.

SUGIMURA, Y.; MURAKAMI, T. Structure and function of the haustorium in germinating Coconut palm seed. JARQ, Paris, n.24, p.1-14, 1990.

TOMLINSON, P.B The structural biology of palms. Oxford: Clarendon Press, 1990. 460p. 